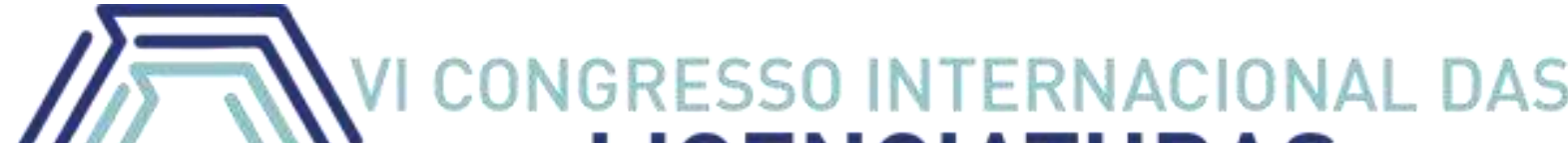 LICENCIATURAS COINTER - PDVL 2019
}

\section{O ENSINO DA CARTOGRAFIA NO ENSINO MÉDIO: ENTRE DESAFIOS E POSSIBILIDADES}

\section{LA ENSEÑANZA DE LA CARTOGRAFÍA EN LA ESCUELA SECUNDARIA: ENTRE DESAFÍOS Y POSIBILIDADES}

\section{THE TEACHING OF CARTOGRAPHY IN HIGH SCHOOL: BETWEEN CHALLENGES AND POSSIBILITIES}

\author{
Apresentação: Comunicação Oral \\ Wagner Salgado da Silva ${ }^{1}$; Ana Paula Torres de Queiroz ${ }^{2}$ \\ DOI: https://doi.org/10.31692/2358-9728.VICOINTERPDVL.2019.0034
}

\begin{abstract}
Resumo
O estudo tem como objetivo geral analisar as relações existentes entre a influência da formação inicial docente, as práticas pedagógicas cartográficas e as concepções de ensino. Para o desenvolvimento desta pesquisa, adotou-se o estudo de caso como método. A abordagem utilizada foi do tipo qualitativa. A pesquisa foi desenvolvida nestas instituições: Escola de Referência em Ensino Médio (EREM) Trajano Chacon, Escola Estadual Barros Carvalho e na Escola Técnica Estadual Professor Lucilo Ávila Pessoa - ETEPLAP. As duas (02) primeiras estão situadas no bairro do Cordeiro e, essa última, no bairro da Iputinga. Ambos os bairros, integram à cidade do Recife, capital do estado de Pernambuco. Os sujeitos da pesquisa são três (03) professores que lecionam a disciplina de Geografia nas turmas de terceiros $\left(3^{\circ}\right)$ anos do Ensino Médio nas escolas antes citadas. Executou-se observações sistemáticas e assistemáticas para análise da prática pedagógica. Entrevistas semiestruturadas também foram utilizadas para $\mathrm{o}$ desenvolvimento deste estudo. No total, foram aplicadas doze (12) perguntas. Assim, divididas, de forma equivalente, aos três (03) docentes que fizeram parte deste trabalho. Esta pesquisa aponta para uma necessidade de reflexão pela professora $01(\mathrm{P} 1)$ e, sobretudo, pelo professor 02 (P2), no que cerne às suas aulas, tendo em vista que estão longes de serem as ideais. Nesse sentido, sugere-se a $\mathrm{P} 1$ e, principalmente, ao $\mathrm{P} 2$, a ressignificação de suas práticas, pois, em momento algum, chegaram a alcançar, de fato, uma aprendizagem efetiva. Novas pesquisas podem ser realizadas a partir dos dados obtidos neste estudo, através do aprofundamento acerca de estudos sobre a relação entre a influência da formação inicial dos educadores, os aspectos contidos em suas práticas de ensino e no processo de aprendizagem, além da dinâmica e da estrutura escolares.
\end{abstract}

\footnotetext{
${ }^{1}$ Graduando do Curso de Licenciatura em Geografia do Instituto Federal de Educação, Ciência e Tecnologia de Pernambuco - IFPE - Campus Recife.

E-mail: wagnersalgado@hotmail.com.br

${ }^{2}$ Professora Mestra do Curso de Licenciatura em Geografia do Instituto Federal de Educação, Ciência e Tecnologia de Pernambuco - IFPE - Campus Recife.

E-mail: anaqueiroz@recife.ifpe.edu.br
} 
Palavras-Chave: Cartografia, ensino, Geografia.

\title{
Resumen
}

El estudio tiene como objetivo analizar las relaciones entre la influencia de la formación inicial del profesorado, las prácticas pedagógicas cartográficas y las concepciones docentes. Para el desarrollo de esta investigación, el estudio de caso fue adoptado como método. El enfoque utilizado fue cualitativo. La investigación se desarrolló en estas instituciones: la Escuela de Referencia de la Preparatoria Trajano Chacon (EREM), la Escuela Estatal Barros Carvalho y la Escuela Técnica Estatal Profesor Lucilo Ávila Pessoa - ETEPLAP. Los dos primeros (02) se encuentran en el distrito de Cordeiro y el último en el barrio de Iputinga. Ambos barrios son parte de la ciudad de Recife, capital del estado de Pernambuco. Los sujetos de investigación son tres (03) maestros que enseñan la disciplina de Geografía en las clases de tercer (3er) año de secundaria en las escuelas mencionadas anteriormente. Se realizaron observaciones sistemáticas y no sistemáticas para analizar la práctica pedagógica. Las entrevistas semiestructuradas también se utilizaron para el desarrollo de este estudio. En total, se aplicaron doce (12) preguntas. Por lo tanto, dividido, por igual, a los tres (03) maestros que formaron parte de este trabajo. Esta investigación apunta a una necesidad de reflexión por parte del profesor $01(\mathrm{P} 1)$ y, sobre todo, por parte del profesor $02(\mathrm{P} 2)$, con respecto a sus clases, ya que están lejos de ser ideales. En este sentido, se sugiere a P1 y, especialmente, a P2, la resignificación de sus prácticas, ya que en ningún momento lograron un aprendizaje efectivo. Se pueden realizar nuevas investigaciones a partir de los datos obtenidos en este estudio, profundizando los estudios sobre la relación entre la influencia de la educación inicial de los educadores, los aspectos contenidos en sus prácticas de enseñanza y el proceso de aprendizaje, y la dinámica y estructuras escolares.

Palabras Clave: Cartografía, enseñanza, Geografía.

\begin{abstract}
The study aims to analyze the relationships between the influence of initial teacher education, cartographic pedagogical practices and teaching conceptions. For the development of this research, the case study was adopted as a method. The approach used was qualitative. The research was developed in these institutions: Trajano Chacon High School Reference School (EREM), Barros Carvalho State School and Professor Lucilo Ávila Pessoa State Technical School - ETEPLAP. The first two (02) are located in the district of Cordeiro and the latter in the neighborhood of Iputinga. Both neighborhoods are part of the city of Recife, capital of the state of Pernambuco. The research subjects are three (03) teachers who teach the discipline of Geography in the classes of third (3rd) years of high school in the schools mentioned above. Systematic and unsystematic observations were performed to analyze the pedagogical practice. Semi-structured interviews were also used for the development of this study. In total, twelve (12) questions were applied. Thus, divided, equally, to the three (03) teachers who were part of this work. This research points to a need for reflection by teacher 01 (P1) and, above all, by teacher 02 (P2), regarding their classes, considering that they are far from ideal. In this sense, it is suggested to P1 and, especially, to P2, the resignification of their practices, since at no time did they actually achieve effective learning. New research can be performed from the data obtained in this study, by deepening studies on the relationship between the influence of initial education of educators, the aspects contained in their teaching practices and the learning process, and the dynamics and school structures.
\end{abstract}

Keywords: Cartography, teaching, Geography. 


\section{Introdução}

Este artigo apresenta resultados do projeto de pesquisa: "novas perspectivas de ensino e avaliação: concepções, práticas, estratégias e repercussões". Sabe-se da importância de promover um ensino de qualidade em todas as etapas educacionais, a fim de alcançar uma aprendizagem com plena efetividade. Para isso, um dos pontos indispensáveis, é uma formação inicial em determinada área do saber que o educador a leciona. Isso evita o docente não possuir propriedade na ciência que ensina.

Quando o professor ensina uma determinada ciência que não possui formação na mesma, é comum que suas aulas não se tornem significativas, ao ponto de não atrair os educandos. Assim, a tendência é que sua prática pedagógica se respalde num modelo de ensino convencional, onde mais características de práticas tradicionais prevaleçam, uma vez que não terá propriedade suficiente para construir o conhecimento do saber que ministra.

Nesse sentido, sua prática profissional estará pautada na Educação Bancária, criticada por Freire (1987). Nessa perspectiva do ensino, a transmissão exaustiva, desgastante e monótona de conteúdos, além de trabalhá-los de maneira descritiva, superficial e bem simples, considerar que os educandos são depósitos para os conteúdos transmitidos, o educador o único detentor do saber, o único que sabe, e os discentes os que não sabem, são um dos aspectos contidos na Educação "Bancária".

De modo bem oposto, encontra-se a Educação Libertadora ou Problematizadora, proposta por Freire (1987), como solução à substituição de um ensino "bancário": opressor, tradicional e reacionário. A Educação Libertadora ou Problematizadora, é uma concepção com um viés crítico, embasada na autonomia, emancipação e transformação dos indivíduos. É uma perspectiva do ensino de caráter revolucionário.

Quando o docente é formado na mesma área do conhecimento que ensina, além de gostar do que faz e ter melhores condições para exercer sua função, a tendência é que suas aulas, de fato, tornem-se significativas e efetivas. É dessa forma que Freire (1996) considera que houve o exercício da docência em sua plenitude, com máxima eficiência.

A maneira que a Cartografia é utilizada no ensino da Geografia, é o que a torna ou não atrativa aos olhos dos educandos. Uma abordagem cartográfica por meio do espaço vivido pelos discentes, dará mais sentido e significado à aprendizagem nas aulas. A habilidade de leitura 
crítica de representações cartográficas no ensino da Geografia pelos estudantes, permite-os obter a capacidade de delimitar e compreender fenômenos geográficos no espaço.

As contribuições adquiridas desde 2016, como participante do Programa Institucional de Bolsas de Iniciação Científica - PIBIC, foi o primeiro motivo de interesse para o desenvolvimento desta pesquisa. A literatura estudada e os procedimentos metodológicos executados e, assim, alcançados, desde o referido ano, foram essenciais à apropriação efetiva da temática pelo pesquisador.

Esse motivo, somado às observações da prática profissional docente, realizadas nos Estágios Supervisionados, foi o segundo, acerca da dificuldade pedagógica na articulação dos conhecimentos básicos cartográficos nas aulas de Geografia. Os conhecimentos básicos da Cartografia são pertinentes à ciência geográfica, com vistas à promoção de um ensinoaprendizagem com maior significância e efetividade.

Diante da dificuldade de muitos professores de Geografia no ensino da Cartografia, considerada um saber fundamental e potencializador ao ensino da Geografia escolar, torna-se importante responder ao seguinte problema de pesquisa: de que forma a Cartografia escolar, no ensino da Geografia, contribui para uma aprendizagem crítico-reflexiva no Ensino Médio?

Com base no que foi exposto até aqui, tem-se, como objetivo geral, analisar as relações existentes entre a influência da formação inicial docente, as práticas pedagógicas cartográficas e as concepções de ensino.

Como objetivos específicos, identificar as concepções de ensino dos professores. Compreender a influência da formação acadêmica na prática de ensino de Cartografia dos professores. E, analisar as inter-relações no que cerne à influência da formação acadêmica no atual exercício docente, à prática pedagógica de Cartografia desenvolvida em sala de aula e à concepção de ensino nas aulas dos educadores, como fatores impactantes na vivência de uma perspectiva de ensino mais inovadora e atrativa.

\section{Fundamentação Teórica}

A Cartografia entendida como um saber técnico, matemático, complexo e de difícil compreensão, encaixa-se numa visão tradicional de sua história ao longo do tempo. Segundo Matias (1996), a visão tradicional da Cartografia era compreendida até à década de 1960, e que, a partir dessa época, essa ciência começou a adquirir uma abordagem mais crítica. 
De modo geral, em sua história tradicional, a Cartografia era entendida por esse viés, porque a preocupação era acerca, principiante, da estética dos mapas, como principal elemento. Em seguida, dissipou-se uma visão cartográfica mais técnica. Nesse sentido, a tecnicidade fazia parte da produção dos mapas. As principais finalidades dos mapas, e talvez as únicas, eram a estética e a tecnicidade ao elaborá-los. Tudo indica que não havia mais aspectos a serem considerados na construção desses objetos de representação gráfica (Ibid., 1996).

Ainda com Matias (1996), a partir de 1966, a Cartografia teve uma nova roupagem. Além de considerá-la somente através da estética e da tecnicidade, antes de 1960, a partir de 1966, a difusão do conhecimento geográfico, passou a ser um marco também fundamental na comunicação visual cartográfica.

Isso quis dizer que, a partir de 1966, os fenômenos geográficos passaram a serem lidos e interpretados, também, pela Cartografia. As representações cartográficas, sobretudo, os mapas, foram essenciais para atingir a finalidade de compreensão espacial geográfica. Com isso, a obtenção de dados e informações pela interpretação do espaço seriam transmitidos à sociedade. Assim, a Cartografia se tornou um importante meio de comunicação visual interpretativo de signos, símbolos e objetos contidos nas inúmeras representações gráficas.

A partir de 1966, a Cartografia recebeu sua primeira definição oficial, a saber:

... o conjunto dos estudos e das operações científicas, artísticas e técnicas que intervêm a partir dos resultados de observações diretas ou da exploração de uma documentação, em vista da elaboração e do estabelecimento de mapas, planos e outros modos de expressão, assim como de sua utilização. (ASSOCIAÇÃO CARTOGRÁFICA INTERNACIONAL - ACI, 1973, apud MATIAS, 1996, p. 46-47).

A Cartografia é um relevante saber para o ensino, por representar análises geográficas, por permitir a leitura e interpretação de fenômenos geográficos e por haver pouco trabalho no que cerne à alfabetização, ao letramento e à linguagem cartográficos. (CASTELLAR, 2011).

Segundo Freire (1996), o educador deve realizar uma autoavaliação a respeito de sua prática pedagógica. Só mediante uma reflexão crítica sobre suas práticas de ensino, é que o ensino-aprendizagem será alcançado de maneira efetiva. Com a reflexão crítica diária da prática pedagógica, a tendência é que as próximas aulas se tornarão, de fato, significativas.

Ainda com Freire (1996), quando o ensino não corresponde a uma aprendizagem significativa, o mesmo não foi, de fato, efetivo, ao passo que não houve a garantia concretizada da aprendizagem. Nesse sentido, o referido autor acredita que o papel docente não foi efetuado 
de modo claro e objetivo, por acreditar que a aprendizagem não foi alcançada em sua plenitude. Assim, ele considera que "não há docência sem discência". (FREIRE, 1996, p. 12).

Concebe-se que não importam os caminhos que o educador percorra e os meios utilizados por ele para chegar ao final de cada um, mas sim, se a aprendizagem foi, de fato, alcançada de forma plena e efetiva.

Um dos pontos essenciais da Teoria Socioconstrutivista, é o engajamento ativo entre educandos/educadores e educandos/educandos. Para Vygotsky (1982), esse engajamento é fundamental para a construção do conhecimento, visto que a interação entre os sujeitos, é peça chave para um ensino-aprendizagem significativo.

Pensar que o educando é um mero acumulador de conhecimento oriundo da transmissão de conteúdos pelo professor, integra-se a práticas de ensino de modelos convencionais, que o considera um ser passivo no processo de ensino-aprendizagem. Pensamento bastante contrário no Socioconstrutivismo, onde o considera um ser ativo, participante, interativo e protagonista no referido processo.

Cavalcanti (2012) fala que a essa teoria, tem como uma das principais dimensões do processo de ensino-aprendizagem, de forma significativa, o cotidiano de vida dos educandos (espaço vivido). O espaço vivido pelos discentes é um conceito geográfico indispensável à efetivação significativa desse processo. A autora também ressalta a relevância de execução da problematização em todas as aulas do início ao fim.

A Educação Libertadora ou Problematizadora proposta por Freire (1987), assemelha-se à Teoria Socioconstrutivista, no que diz respeito à abordagem no processo de ensinoaprendizagem. É uma concepção de ensino pautada na criticidade, reflexão, revolução, progresso e desopressão.

Chevallard (1991, apud MATOS FILHO; et al., [2008]), realça que o conhecimento acadêmico não chega à sala de aula de forma científica. $O$ licenciando o recebe e o transforma em conteúdo escolar. 'É então que entra em cena a Transposição Didática. Esse processo diz respeito à passagem do Saber de uma Instituição à outra; passagem esta que imprime novas formas [...]”. (BROUSSEAU, 1986, apud MATOS FILHO; et al., [2008]).

Concebe-se, assim, a importância de uma transposição didática dos conteúdos científicos por professores de qualquer área de ensino, com vistas a uma aproximação efetiva entre estas perspectivas educacionais: ensino e aprendizagem. À medida que o educador constrói o conhecimento por meio do espaço vivido pelos educandos, por exemplo, a 
probabilidade de atratividade e, por decorrência, a chance de conseguir a atenção deles, serão significativas, tendo em vista a utilização em aula de aspectos do cotidiano vivido por eles.

Mas, para isso, é fundamental que a formação inicial do docente seja na mesma área lecionada por ele, pois é só assim que, de fato, o conhecimento será construído com total propriedade. Um professor que ensina um determinado saber distinto do qual se formou, está propenso a cometer alguns equívocos e falhas, ao passo que não possui conhecimento afundo do mesmo, além de estar distante de sua alçada científico-profissional, à qual se formou.

A transposição didática, a Educação Libertadora, Problematizadora e a Teoria Socioconstrutivista, são fundamentais para conceber, idealizar e ter, na prática, um ensinoaprendizagem de qualidade em todos os sentidos. Pois, buscam, de maneira incessante, romper com metodologias embasadas em modelos de ensino convencionais, ao possuírem, em seus propósitos, métodos e técnicas de ensino eficientes, capazes de solucionar e suprir eventuais empecilhos e lacunas bastante presentes na realidade escolar pública brasileira.

Os propósitos apresentados por Chevallard e Brousseau, Paulo Freire e Lev Vygotsky, associados ao ensino com representações cartográficas, passa-nos à compreensão de que é uma das mais variadas formas para o efetivo alcance do ensino. Pois, a maneira da abordagem do conhecimento cartográfico de forma criativa, contextualizada, crítica e reflexiva, inclui-se nessas propostas pedagógicas e, assim, torna-a atrativa aos educandos. A prática pedagógicocartográfica é um elemento essencial, quando se trata de envolvê-la com determinados conteúdos geográficos em sala de aula.

\section{Metodologia}

Inicialmente, para o desenvolvimento deste estudo, foi realizado um levantamento bibliográfico, onde o pesquisador reuniu as principais obras a respeito do tema de interesse. $\mathrm{O}$ método adotado foi o estudo de caso. De acordo com Gil (2002), esse método é caracterizado pelo aprofundamento do objeto de estudo, a fim de conhecê-lo ao máximo.

A abordagem utilizada foi do tipo qualitativa. Esse tipo de abordagem visa explicar a inter-relação dinâmica entre sujeitos e fenômenos. A análise de fenômenos e, segundo Minayo (1994), a consideração de significados, sentidos, princípios, valores, hábitos, costumes, tradições..., são características dessa pesquisa. Centra-se mais na subjetividade. 
A pesquisa foi desenvolvida nestas instituições: Escola de Referência em Ensino Médio (EREM) Trajano Chacon, Escola Estadual Barros Carvalho e na Escola Técnica Estadual Professor Lucilo Ávila Pessoa - ETEPLAP. As duas (02) primeiras estão situadas no bairro do Cordeiro e, essa última, no bairro da Iputinga. Ambos os bairros, integram à cidade do Recife, capital do estado de Pernambuco.

Os motivos pelos quais tais campos de pesquisa foram escolhidos são: os Estágios Supervisionados III e IV realizados na ETEPLAP; a proximidade geográfica entre as escolas; e a distinção categórica entre as mesmas; ao passo que uma é técnica, outra é de referência e outra é estadual comum (de horário regular).

A fim de não haver dúvidas e obter maior entendimento, os docentes foram classificados desta forma: professora 01 (P1), professor 02 (P2) e professora $03(\mathrm{P} 3)$. A P1 leciona na EREM Trajano Chacon, o P2, na Escola Estadual Barros Carvalho, e a P3, na ETEPLAP.

A amostra foi definida como intencional, pois os educadores selecionados, possuem as características preestabelecidas para a participação neste estudo: três (03) professores que lecionam a disciplina de Geografia nas turmas de terceiros $\left(3^{\circ}\right)$ anos do Ensino Médio nas referidas escolas.

Foram selecionadas, somente, as turmas de terceiros $\left(3^{\circ}\right)$ anos do Ensino Médio de cada escola, porque acreditamos que os educandos estão mais amadurecidos, ao considerar sua faixa etária e o último ano de conclusão da educação básica por eles. Outro ponto que consideramos pertinente, para a seleção, apenas, dessas turmas, foram os conteúdos, pois são de cunho político e socioeconômico, o que viabiliza o trabalho com as representações cartográficas, por meio da criticidade e reflexão.

Na EREM Trajano Chacon, foram observadas as aulas nos terceiros $\left(3^{\circ}\right)$ anos B e D, somente. Não foram observadas as aulas nas turmas A e C, porque nas quartas-feiras à tarde, dia e turno em que as aulas de Geografia nessas turmas eram ministradas, o pesquisador assistia às aulas do componente curricular Estratégias de Educação Ambiental, ofertado pelo curso de Gestão Ambiental, do IFPE - Campus Recife. Havia outra educadora que também lecionava Geografia no Ensino Médio, porém, nos primeiros $\left(1^{\circ}\right)$ e segundos $\left(2^{\circ}\right)$ anos.

A Escola Estadual Barros Carvalho só possuía duas (02) turmas (A e B) de terceiros ( $\left.3^{\circ}\right)$ anos nos turnos da manhã e tarde, ao passo que essa instituição funcionava em horário regular. Contudo, só foram observadas as aulas nas turmas do turno da manhã. Não nas do turno da tarde, porque as aulas de Geografia eram ministradas nas terças e quartas-feiras à tarde, por 
uma determinada professora. Nas terças-feiras, o pesquisador estava em reuniões de sua monitoria e, nas quartas, havia o mesmo caso antes elucidado, relativo à EREM Trajano Chacon.

A única instituição que teve as aulas de Geografia observadas em todas as turmas de terceiros $\left(3^{\circ}\right)$ anos foi a ETEPLAP, pois os horários das mesmas não coincidiram com nenhum imprevisto. Nessa escola havia quatro (04) turmas de terceiros $\left(3^{\circ}\right)$ anos: duas (02) A e duas (02) B. As quatro (04) integradas aos cursos Técnicos de Administração e Redes de Computadores, divididas na mesma proporção para cada um.

O período de execução das observações foi entre os meses de fevereiro e maio de 2019. Um total de vinte e oito (28) aulas foram observadas na EREM Trajano Chacon. Em cada turma, quatorze (14). Na Escola Estadual Barros Carvalho, foram trinta e seis (36). Em cada turma, dezoito (18). Na ETEPLAP, foram sessenta e quatro (64). Em cada turma, dezesseis (16).

Vale destacar que mais aulas em todas as escolas não foram observadas, porque ocorreram muitos contratempos, como período de execução de provas e outros imprevistos corriqueiros do cotidiano escolar e pessoais dos educadores.

Outro motivo, foi identificar, de forma separada, uma grande similaridade metodológica no que cerne às aulas dos docentes no decorrer do período letivo, no espaço de tempo em que foram observadas pelo pesquisador, visto que seguiam, basicamente, a mesma lógica de trabalho, contemplada do início ao final das observações. A metodologia empregada em sala de aula por cada um, mudava muito pouco de uma aula à outra e, por isso, não havia mais a necessidade de observá-las.

As análises das aulas foram feitas através de observações sistemáticas e assistemáticas. Segundo Gerhardt et al. (2009), o tipo de observação sistemática, permite ao pesquisador maior precisão e exatidão na investigação e análise de aspectos imprescindíveis à obtenção de dados fundamentais, para o desenvolvimento da pesquisa. Pois, não se dispensa, em hipótese alguma, da elaboração prévia de um planejamento para sua efetiva execução.

O tipo de observação assistemática, permite ao pesquisador maior liberdade no momento de sua execução, sem perder de vista a manifestação e atuação dos fenômenos e o controle das informações adquiridas (Ibid., 2009). Nesse sentido, não são permitidos planejamentos prévios de quaisquer naturezas.

Além da referida técnica de pesquisa, como um dos instrumentos para coleta de dados, foi produzido um roteiro com perguntas para a execução de uma entrevista semiestruturada. No 
total, foram aplicadas doze (12) perguntas. Assim, divididas, de forma equivalente, aos três (03) docentes que fizeram parte desta pesquisa.

Conforme Gerhardt et al. (2009, p. 72), a entrevista semiestruturada é um tipo de técnica de pesquisa, onde "o pesquisador prepara um conjunto de perguntas (roteiro) sobre o tema abordado, mas permite e, às vezes, até incentiva, que o entrevistado fale livremente sobre assuntos que vão surgindo como desdobramentos do tema principal”.

Além das observações e da entrevista executadas, seriam analisados os Projetos Pedagógicos das instituições em que os professores atuam. No entanto, isso não foi possível, porque esses documentos não foram disponibilizados ao pesquisador. O Projeto Pedagógico é considerado parte essencial dos instrumentos para coleta de dados.

\section{Resultados e Discussão}

A fim de obter uma melhor compreensão acerca das práticas dos professores, serão apresentadas suas respostas relativas às perguntas contidas na entrevista, além de compará-las e contextualizá-las com as observações realizadas a despeito de suas aulas.

"Você é formado(a) em Geografia? Licenciatura ou Bacharel?".

A P1 informa que "não, sou formada em História. Licenciatura em História".

O P2 confirma que "não. Minha formação é História. Licenciatura Plena".

A P3 elucida que é "formada em Geografia. Licenciatura Plena".

A segunda pergunta: “o que você entende sobre representação cartográfica?”.

A P1 disse o seguinte: "entendo que são as representações de mapas, né, em todo o seu contexto visual [...]. Pode ser uma representação específica de relevo, de hidrografia. Pode ser uma representação específica de clima [...]”.

O P2 “acredita que a representação cartográfica tá presente no nosso dia-a-dia, mas que tem a finalidade de nos mostrar um ponto mais seguro e mais exato, como, por exemplo, do ponto A ao ponto B (A e B: corpo, objeto...), uma trajetória".

Já a P3 entende que "é a representação da determinada área ou espaço, com delimitações menores, para maior compreensão do que está a nossa volta".

Para a P1, representações cartográficas se restringem aos mapas. Mas, pelos exemplos que ela citou, percebe-se que a mesma deve entender sobre representações. 
Já o P2, talvez não possua tanto entendimento a despeito do que seja uma representação cartográfica, pois, para ele, tem a finalidade de mostrar a trajetória de um corpo, objeto e/ou qualquer outro aspecto de um ponto a outro(s).

Percebe-se que a P3 entende, de fato, o que seja uma representação cartográfica, ao passo que, passou-nos a impressão de compreensão de fenômenos geográficos no espaço, através de uma determinada realidade reduzida num material gráfico.

Embora entenda um pouco, de modo geral, o que seja uma representação cartográfica, a P1, sequer, em suas aulas, utilizou um tipo de representação. Algumas delas dariam até para ela usar. Um dos grandes problemas deve ser em virtude de sua formação inicial (Licenciatura em História), pois, em função disso, deve possuir dificuldade para articular as representações com os conteúdos geográficos.

Outra questão, por não ter utilizado nenhum tipo de representação, pode ter sido os conteúdos geográficos lecionados em sala de aula na época das observações executadas pelo pesquisador, que não eram propícios à articulação com as representações gráficas.

Outro problema, deve ter sido a escola possuir, apenas, três (03) tipos de representações: um (01) mapa-múndi, um (01) mapa físico e um (01) globo terrestre. Com isso, é quase impossível utilizar, em diversos conteúdos de Geografia, poucas e mesmas representações, pois os assuntos são bastante dinâmicos e o espaço geográfico está em processo contínuo de modificação. Cada conteúdo de Geografia pode necessitar de materiais gráficos diversificados.

Além disso, o desinteresse, a conversa e as brincadeiras ao extremo pelos educandos, atrapalhava-a e a deixava com pouca motivação para lecionar. Outras questões, como salários baixos e poucos recursos disponíveis na escola para a sua prática pedagógica, também foram fatores determinantes para tal desmotivação.

O nível cultural dos discentes era baixo. Pode ser que também por isso, não havia interesse dos estudantes pelas aulas e, assim, impactava, de modo direto, num mau comportamento e ausência de interação e participação deles, além de debate e discussão em sala de aula, à medida que o conhecimento era construído.

A estrutura física da EREM Trajano Chacon também não era a ideal, inclusive, das salas de aula. Era outro ponto que impactava, de maneira negativa, o processo de ensinoaprendizagem em sua plenitude, de modo significativo.

Apesar de todos esses e outros problemas e questões existentes na escola, às vezes, suas aulas eram muito interessantes e ricas em conhecimento, pois se aproximavam de sua formação 
inicial (visto que envolviam a área de Geografia Humana). Nesse sentido, tinha afinidade e gostava dos conteúdos. Isso era perceptível. Mas, na maioria das vezes, suas aulas eram insipientes, descritivas e superficiais.

Bem como à P1, o P2 também possui formação inicial em Licenciatura em História e isso, devidamente, pode ser um motivo a considerar-se, em relação à dificuldade de articulação de algumas representações gráficas, com alguns conteúdos da ciência geográfica em suas aulas.

Ele só utilizou alguns tipos de representações em uma de suas aulas. Não nas demais, porque, conforme ele afirmou, utiliza-os de acordo com determinado conteúdo a ser ministrado em sala de aula e quando o mesmo é possível para tal execução.

Todavia, utilizou-as de modo muito insipiente, descritivo e superficial. Assim, com ausência de dinâmica, criticidade, reflexão e contextualização. Porém, o conteúdo possibilitava o trabalho com esses últimos aspectos, sobretudo, com os três (03) últimos.

O conteúdo ministrado integrava à área de Geografia Humana. Por ele ser historiador, possibilitou-o, e muito, a construção do conhecimento geográfico naquele momento. Entretanto, faltou-lhe explorar, de forma efetiva, as representações a partir daqueles aspectos essenciais ao processo de ensino-aprendizagem.

De acordo com ele, a escola somente possuía um tipo de representação cartográfica: globo terrestre. A ausência de recursos didáticos cartográficos na escola, também era um dos motivos que o impediam para construir o conhecimento geográfico em sala de aula por meio da articulação cartográfica.

A Falta de outros recursos de modo genérico, salário incompatível com o exercício da docência e com a demanda de atividades/turmas e cargas horárias de trabalho elevadas, eram fatores que o desmotivavam e, assim, implicavam, de maneira direta e negativa, em sua prática.

Isso, juntamente com os problemas em sala de aula causados pelos estudantes, entre outros aspectos presentes numa escola pública na atualidade, impediam-no, tudo indica, de preparar aulas atrativas e significativas.

Suas aulas eram sempre maçantes, entediantes, desagradáveis, sem atratividade e desprovidas de sentidos e significados. Essas questões impactavam, de forma negativa, na relação educador-educando em sala de aula, que não era pacífica.

De acordo com Freire (1996), uma possível solução para o referido educador, deve ser acerca da execução de reflexões críticas diárias a respeito de suas práticas pedagógicas cotidianas, ao passo que a tendência é que suas aulas se tornem significativas. 
Esse autor acredita que a atividade docente deve sempre ser ressignificada, quando a metodologia empregada não atinge a aprendizagem com a devida eficiência. Quando um dos problemas é o ensino de um saber distinto ao qual o educador é formado, a ressignificação de suas práticas, é um dos passos cruciais à efetividade no processo de ensino-aprendizagem. Nesse sentido, com a discência alcançada em sua plenitude, o exercício docente foi efetivado.

Além do problema de ser formado em História e ensinar Geografia, os educandos não cooperavam, pois sempre, não prestavam atenção, conversavam e brincavam demais. Essas questões sempre atrapalhavam suas aulas e, assim, incomodavam-no e deixavam-no quase sempre desmotivado.

Bem diferente das demais escolas aqui apresentadas, as turmas dos terceiros $\left(3^{\circ}\right)$ anos A e B do turno da manhã da Escola Estadual Barros Carvalho, possuíam o nível cultural bem mais baixo, pois a falta de interesse, atenção, interação, participação, debate e discussão em sala de aula era bastante aquém.

A estrutura física dessa escola também deixa muito a desejar, pois as condições externas e internas à mesma são muito precárias, inclusive, as de dentro das salas de aulas. É visível a desmotivação do educador e dos educandos, em função da ausência de recursos e da precariedade dos que ainda estão disponíveis. Em todos os aspectos, essa escola era a mais preocupante e, quem sabe, até alarmante. De fato, essas questões aqui propostas, impactavam o processo de ensino-aprendizagem.

Já a P3 é licenciada em Geografia. Também é a educadora que ensina a Geografia. De acordo com sua resposta, a mesma diz que utiliza representações cartográficas em sala de aula.

Uma das formas mais eficientes no ensino-aprendizagem da Geografia escolar, por meio da Cartografia, para a compreensão do espaço geográfico, faz-se acerca da linguagem cartográfica. Certos fenômenos geográficos da realidade espacial vivida pelos educandos, são contemplados por eles em função da compreensão obtida acerca desse processo. Castellar (2017) informa que, para que esse processo se consolide na aprendizagem, é fundamental que o educador crie condições de leitura e interpretação críticas de representações cartográfica.

A habilidade de leitura crítica de representações cartográficas no ensino da Geografia, permite ao estudante o privilégio de esmiuçar e desmistificar certos aspectos impostos pelos agentes sociais na contemporaneidade. $\mathrm{O}$ educando, nesse nível, passa a ter a capacidade de compreensão dos fenômenos existentes no seu espaço vivido e de sua distribuição espacial. 
Contudo, em nenhum momento, ela utilizou, sequer, um tipo de representação gráfica nas suas aulas. Apesar de ser formada em Geografia, pode ser que ela ainda possua dificuldade em trabalhar a Cartografia em sala de aula. Essa ciência é bastante complexa e de difícil compreensão. Não é à toa que muitos profissionais da área da Geografia (bacharéis e licenciados), inclusive, têm dificuldades na produção cartográfica nas aulas de Geografia, desde a época em que cursavam suas graduações.

Também não foram utilizadas, segundo ela, porque as representações cartográficas não tornam as aulas dinâmicas. As representações cartográficas, como um dos vieses da Cartografia, podem, de fato, potencializar as aulas de Geografia.

A partir das representações sociais e de mapas mentais, por exemplo, as aulas podem ganhar atratividade, sentido e significância, pois serão trabalhadas com aspectos e fenômenos geográficos presentes no espaço vivido.

Outro ponto relevante que a decidiu não utilizar representações, foi considerar que, nem todas as aulas de Geografia, são apropriadas à utilização desses tipos de materiais gráficos, uma vez que, consideram-na, incompatíveis com determinados conteúdos em sala de aula.

A pequena disponibilidade de recursos pedagógicos cartográficos na escola, pode ser mais um motivo para ela não utilizá-los nas suas aulas de Geografia, pois tudo indica, que se relacionam, somente, com alguns conteúdos, à medida que são bastante específicos e, assim, inviáveis ao ensino cartográfico.

O livro didático era o recurso pedagógico mais utilizado por ela. Em muitos conteúdos abordados, com essa ferramenta didática, havia algumas representações, como mapas, por exemplo, que se articulavam aos conteúdos, mas, nem ao menos, foram mencionados.

As duas (02) turmas ( $3^{\circ} \mathrm{A}$ e B) do Ensino Médio Integrado ao curso Técnico de Redes de Computadores da Escola Técnica Estadual Professor Lucilo Ávila Pessoa - ETEPLAP, em relação aos quesitos conversa e brincadeira, são as mais complicadas para todos os professores dessa escola, inclusive, para a de Geografia.

As aulas de Geografia nessas turmas eram sempre atrapalhadas pelos estudantes. Muitos deles sempre desinteressados, sobretudo, os do $3^{\circ}$ ano B. Contudo, a professora de Geografia nunca deixou a desejar em nenhum aspecto, embora sem ter utilizado nenhum tipo de representação e muitos educandos desinteressados pelas suas aulas.

A explicação para o desinteresse de muitos deles em sala de aula, deve ter sido em virtude da ausência de disciplina e compromisso (devido à faixa etária, sobretudo) pelos 
educandos, pois muitas vezes negligenciavam as aulas de Geografia. Tudo indica que também atrapalhavam e negligenciavam as aulas de outros educadores dos demais saberes, pois todos reclamavam do comportamento deles em suas aulas.

No que diz respeito às aulas de Geografia, não há motivos para os estudantes as atrapalharem e as negligenciarem, haja vista que, as aulas, são, de fato, significativas, embora com a convivência com tais problemas elucidados.

Já no tocante às duas (02) turmas $\left(3^{\circ} \mathrm{A}\right.$ e B) do curso Técnico em Administração da referida instituição, só às vezes que as aulas eram pouco atrapalhadas pelas conversas e brincadeiras dos educandos, mas nada que a impedisse de ensinar de maneira significativa. Apenas alguns educandos dessas turmas se desinteressavam pelas aulas.

A maioria dos estudantes das quatro (04) turmas se interessava, e muito, pelas aulas da educadora de Geografia. Em todas, sempre havia debates, discussões, participação e interação entre educador-educando. Do início ao final das aulas, a docente sempre os instigavam a participarem e a interagirem a todo instante. Suas aulas eram sempre discutidas e debatidas com bastante criticidade e reflexão dos fenômenos.

O espaço, palco recorrente da manifestação e atuação incessante dos fenômenos geográficos, era, de maneira constante, compreendido em sala de aula. Todas as suas aulas seguiam uma lógica efetiva de introdução, desenvolvimento e conclusão de forma contextualizada, crítica e reflexiva. Desse modo que suas aulas eram ministradas, a maioria dos discentes prestava atenção, participava e interagia, pois se sentiam atraídos.

Apesar de alguns empecilhos causados pelos discentes das turmas do curso Técnico em Redes de Computadores, sobretudo, a Geografia era sempre ensinada de modo significativo.

O fato de ser formada em Geografia, ter sempre o desejo de constituir seres críticos, participativos e atuantes na sociedade contemporânea, para reivindicarem, exigirem e irem em busca dos seus direitos e deveres, além de amar a sua profissão, motivavam-na todos os dias para trabalhar em sala de aula. Esses aspectos eram o que a faziam sempre ensinar a ciência geográfica com muita propriedade.

Outro fator que a possibilitava ensinar dessa forma, era o nível cultural dos estudantes, pois, em sua maioria, tinha interesse e, assim, prestava atenção, interagia e participava das aulas. O nível cultural deles era bem mais alto que o dos discentes das escolas de atuação dos outros educadores aqui mencionados. 
Outro ponto que, também, impactava de maneira direta na sua prática pedagógica, era a estrutura física escolar e, sobretudo, das salas de aulas. Cabe destacar que a realidade da ETEPLAP ainda é distante da ideal, mas, ao compará-la com a realidade de outras instituições públicas brasileiras de educação básica, inclusive, com as outras aqui discutidas, está bem à frente das mesmas, pois, em todas as salas de aulas, havia, inclusive, ares-condicionados em bom estado de funcionamento.

Em seguida, perguntou-se: "você considera importante ter cursado disciplinas pedagógicas para a sua prática profissional atual? Por quê?”.

A P1: “[...] dentro da minha prática, aprendi [...] que trazer eles pra dentro da aula, é muito importante. Eles não podem ser ouvintes, têm que ser participativos [...]".

A P1 corrobora que foram extremamente relevantes, para lidar com os inúmeros problemas de uma escola e com determinada faixa etária dos discentes, a fim de torná-los seres mais participativos e atuantes no processo de ensino-aprendizagem.

O P2: "sim, eu acredito que ela é indispensável pra atuação em sala, até a questão humana também, né. Pra que haja uma interação maior entre professor-aluno, acredito que é muito importante, essa parte pedagógica também".

O P2 acredita que são imprescindíveis à atuação profissional em sala de aula, no que diz respeito à valoração dos princípios, valores, essência e sentidos humanos, a fim de que haja uma interação pacífica e harmônica entre educador-educando.

A P3: "não. Porque na realidade, eu ainda acho que a licenciatura é um dom [...]. E a comunicação voltada pra educação, ainda é um dom com plus maior [...]"

Entretanto, a P3 salientou que não considera, pois ela acredita que não há necessidade, uma vez que a carreira docente é um dom. Para ela, esse elemento dispensa a contribuição das disciplinas pedagógicas na formação de um professor.

"Qual a concepção de ensino que você se considera atuar? Por quê?".

A P1 proferiu que atua nas concepções "Socioconstrutivista e Libertadora [...]".

Apesar de ter confirmado em sua resposta que atua em concepções críticas do ensino, não foi contemplado em suas aulas. Pode ter sido em decorrência de numerosos motivos aqui já apresentados. De acordo com as observações realizadas em sala de aula, sua metodologia mais se assenta a um modelo de ensino convencional do que crítico.

Embora na escola que a professora exercia sua profissão havia muitos problemas em variados pontos de vista, que a impediam, tudo indica, de ensinar de maneira significativa, ela, 
em seu exercício profissional, possui o compromisso com uma educação de qualidade em todos os âmbitos, que estão ao seu alcance.

P2: "[...] trabalho justamente com uma forma de promover a democracia dentro da sala de aula. Que eles possam realmente refletir, opinar e se posicionar dentro da sala de aula".

Pelo que o P2 respondeu, ele diz atuar em alguma concepção crítica do ensino. No entanto, a partir das observações de suas aulas, de fato, sua metodologia está sustentada num modelo de ensino convencional, como visto nas análises executadas e propostas no decorrer da segunda $\left(2^{\mathrm{a}}\right)$ pergunta em relação a ele.

A P3 esclareceu que atua na concepção "Socioconstrutivista [...]".

A P3 respondeu que atua na concepção de ensino Socioconstrutivista. No que tange à sua resposta, de fato, alguns aspectos elencados por ela, integram a essa concepção. Quanto ao seu ensino, observado em sala de aula, concebe-se que, muitas questões trabalhadas, estão inseridas no Socioconstrutivismo.

Ela, por exemplo, construía o conhecimento de modo que sempre havia debates, discussões, participações e interações entre ela e os discentes. Esse elo entre educadoreducando, era completado quando tais aspectos citados a despeito deles eram realizados com base na contextualização, criticidade e reflexão dos conteúdos trabalhados. O ensino da P3 era, assim, executado com muita qualidade e eficiência, o que o tornava significativo e atrativo.

A Teoria Socioconstrutivista proposta por Vygotsky (1982), é fundamental para o processo de ensino-aprendizagem, haja vista que percorre um caminho inverso ao de práticas contidas em modelos de ensino convencionais.

Essa concepção de ensino, busca solucionar impasses, preencher lacunas e romper com metodologias apoiadas na descrição, insipiência, monotonia e superficialidade. Bem como à Educação Libertadora ou Problematizadora de Freire (1987), procura romper com ensinos reacionários, sem criticidade e reflexão do espaço vivido pelos educandos.

Seja a concepção proposta por Freire (1987), seja aquela proposta por Vygotsky (1982), respaldam-se na transformação de um ensino com características reacionárias, a fim de tornálo com perspectivas progressivas e revolucionárias. São por essas vertentes educacionais, que os referidos autores acreditam num processo de ensino-aprendizagem com mais efetividade. 


\section{Conclusões}

De acordo com o que foi discutido no texto, concebe-se que quão grandes são os desafios existentes no ensino da Cartografia no Ensino Médio, uma vez que se trata de um saber com considerável complexidade de compreensão, tanto por parte de educadores (formados ou não em Geografia), como por parte de educandos.

Os principais desafios encontrados por P1 e P2, sobretudo, no trabalho com os conhecimentos cartográficos, vão desde à formação inicial, a princípio, até dificuldades como na articulação da Cartografia no ensino da Geografia, além de problemas recorrentes relacionados à profissão: salários muito baixos (bem mais do que os dos efetivos, pois eram contratados), condições de trabalho insuficientes, quantidade de tarefas, de turmas e de carga horária elevadas, além do desinteresse e das interrupções das aulas por parte dos estudantes, com conversas e brincadeiras constantes.

No entanto, as possibilidades de alcançar uma aprendizagem com qualidade no Ensino Médio, por meio da Cartografia, também são consideráveis, pois, com a articulação desse saber ao ensino da Geografia, há muitas alternativas para tal feito.

Fazer relação dos conteúdos geográficos com o espaço vivido pelos educandos, através da Cartografia Social e da construção de um mapa mental com os problemas ambientais, culturais, econômicos, políticos e sociais, por exemplo, são uma das alternativas a serem empregadas pelo educador, com vistas à promoção de um ensino-aprendizagem significativo.

Conforme às observações realizadas da prática da professora da EREM Trajano Chacon (P1) e das aulas do docente da Escola Estadual Barros Carvalho (P2), concebe-se que estão mais respaldadas num modelo de ensino convencional. Esse modelo está mais presente na prática do professor, visto que suas aulas eram sempre sem atratividade, sem criticidade, sem reflexão e desprovidas de sentidos e significados.

Já em relação à educadora da ETEPLAP, suas aulas estão bem mais próximas de um modelo de ensino crítico, tendo em vista que eram sempre dinâmicas, atrativas, interessantes, críticas, reflexivas e significativas.

Tanto a P1, como o P2, possuem formação em Licenciatura em História e lecionam a disciplina de Geografia em seus espaços de atividade profissional. Por serem formados numa ciência e atuarem em outra, compreendeu-se que impactou, de forma direta e negativa, em suas aulas e, inclusive, em suas práticas pedagógicas cartográficas. Pois, sequer, pela docente, um 
tipo de representação cartográfica foi utilizado e, pelo educador, utilizado de maneira insipiente, bem superficial e muito descritiva.

A P3 é formada em Licenciatura em Geografia e a leciona. O fato de ser formada na mesma ciência que ensina, possuir o desejo contínuo de formar cidadãos e, sobretudo, amar a sua profissão, foram fatores determinantes para ela ministrar suas aulas com tamanha qualidade, eficiência e efetividade. Apesar de não ter construído o conhecimento geográfico por meio da Cartografia, em vários momentos, suas aulas sempre permaneceram significativas.

Como se sabe, não foi possível fazer análises com os Projetos Pedagógicos, porque as escolas não os disponibilizaram para tal feito. Sabe-se que o Projeto Pedagógico é considerado um documento indispensável para a identificação e compreensão dos propósitos das instituições em todos os aspectos. Pois, por meio deles, consegue-se pressupor, de fato, o que as escolas concebem, no que se refere à dinâmica escolar e ao processo de ensino-aprendizagem.

Esta pesquisa aponta para uma necessidade de reflexão pela P1 e, sobretudo, pelo P2, no que cerne às suas aulas, tendo em vista que estão longes de serem as ideais. Acerca da reflexão crítica de suas práticas, embora com a evidente dificuldade de lecionar os conteúdos de Geografia e, claro, articulá-los aos conhecimentos cartográficos, pois são licenciados em História, poderá ter uma melhora significativa. Isso será fundamental, visto que os educandos, poderão interessar-se pelas aulas e, assim, o ensino-aprendizagem fluirá de modo efetivo.

Nesse sentido, sugere-se a P1 e, principalmente, ao P2, a ressignificação de suas práticas, pois, em momento algum, chegaram a alcançar, de fato, uma aprendizagem efetiva. Com a reinvenção de suas metodologias em alguns pontos, como, por exemplo, mais problematização em sala de aula e conexão dos conteúdos com o espaço vivido pelos discentes, além da referência à manifestação e ocorrência simultânea de fenômenos geográficos numa escala local à global, suas aulas poderão tonar-se efetivas.

Novas pesquisas podem ser realizadas a partir dos dados obtidos neste trabalho, através do aprofundamento acerca de estudos sobre a relação entre a influência da formação inicial dos educadores, os aspectos contidos em suas práticas de ensino e no processo de aprendizagem, além da dinâmica e da estrutura escolares. Assim, de que modo, essa inter-relação impacta no processo de ensino-aprendizagem, uma vez que, neste trabalho, as análises foram executadas em cima do processo de ensino, apenas. 


\section{Referências}

CASTELLAR, S. M. V. Cartografia escolar e o pensamento espacial fortalecendo o conhecimento geográfico. Revista Brasileira de Educação em Geografia, Campinas, v. 7, n. 13, p. 207-232, jan./jun. 2017.

CASTELLAR, S. M. V. A cartografia e a construção do conhecimento em contexto escolar. In: ALMEIDA. R. D. (org.). Novos Rumos da Cartografia Escolar: currículo, linguagem e tecnologia. 1. ed. São Paulo: Contexto, 2011. p. 121-135.

CAVALCANTI, L. S. O ensino de geografia na escola. Campinas: Papirus, 2012.

FREIRE, P. Pedagogia da autonomia: saberes necessários à prática educativa. São Paulo: Paz e Terra, 1996.

FREIRE, P. Pedagogia do oprimido. 17. ed. Rio de Janeiro: Paz e Terra, 1987.

GERHARDT, T. E.; et al. Estrutura do projeto de pesquisa. In: GERHARDT. T. E.; Silveira. D. T. (org.). Métodos de pesquisa. Universidade Aberta do Brasil - UAB/UFRGS e pelo Curso de Graduação Tecnológica, Planejamento e Gestão para o Desenvolvimento Rural da SEAD/UFRGS. (coord.). Porto Alegre: Editora da UFRGS, 2009.

GIL, A. C. Como elaborar projetos de pesquisa. 4. ed. São Paulo: Atlas, 2002.

MATIAS, L. F. "Por uma Cartografia geográfica - uma análise da representação gráfica na Geografia". Orientador: Marcello Martinelli. 1996. 476, f. Dissertação (Mestrado em Geografia) - Faculdade de Filosofia, Letras e Ciências Humanas - FFLCH, Universidade de São Paulo, São Paulo, 1996.

MATOS FILHO, M. A. S.; et al. A transposição didática em Chevallard: as deformações/transformações sofridas pelo conceito de função em sala de aula. In: VIII

Congresso Nacional de Educação - VIII EDUCERE, Curitiba - PR. Anais do VIII Congresso Nacional de Educação - VIII EDUCERE. p. 1191-1201, [2008]. Disponível em: http://educere.bruc.com.br/arquivo/pdf2008/431_246.pdf. Acesso em: 17 ago. 2019.

MINAYO, M. C. S. (Org.). Pesquisa social: teoria, método e criatividade. 21. ed. Petrópolis: Vozes, 1994.

VYGOTSKY, L. S. Sobranie sochinenii. Problemy obshchei psikhologuii. Pedagoguika: Moscou, 1982b. Tradução em: Obras Escogidas: problemas de psicologia geral. Fuenlabrada, Madrid: Gráficas Rogar, 1982. 